\title{
Disodium Rhodizonate/Reduced Graphene Oxide-Sodium Alginate Composite as a Cathode Material for Sodium-ion Batteries with High Cyclic Performance
}

\author{
Shicheng Tang ${ }^{1}$, Zewei Yuan ${ }^{3}$, Xiangyu Deng ${ }^{1}$ Yue Huang ${ }^{1}$, Guodong Jiang ${ }^{1,2}$, \\ Jian Xiong ${ }^{1,2}$, Han $\mathrm{Wu}^{1}$, Songdong Yuan ${ }^{1,2, *}$ \\ ${ }^{1}$ Hubei Collaborative Innovation Center for High-efficiency Utilization of Solar Energy, Hubei \\ University of Technology, Wuhan, 430068, China. \\ ${ }^{2}$ The Synergistic Innovation Center of Catalysis Materials of Hubei Province, Wuhan 430068, China. \\ ${ }^{3}$ Department of Chemistry, University of Amsterdam, Science Park904, 1098XH, Amsterdam, \\ Netherlands \\ *E-mail: yuansongdong@aliyun.com
}

doi: $10.20964 / 2021.03 .41$

Received: 4 October 2020 / Accepted: 25 December 2020 / Published: 31 January 2021

\begin{abstract}
Organic electrode materials have great application potential in sodium-ion batteries, but solving the cycling performance of organic materials at high current densities is a huge challenge. Here, $\mathrm{Na}_{2} \mathrm{C}_{6} \mathrm{O}_{6} /$ reduced graphene oxide-sodium alginate (SR/RGO-SA) was prepared by antisolvent precipitation and solvothermal methods. The hydrogen bonds formed between SR and RGO-SA and the conductive network of RGO-SA were used to prevent the capacity attenuation caused by pulverization upon prolonged cycling. Versus SR electrodes, the SR/RGO-SA electrode has better cycle performance and rate performance at high current densities. The SR/RGO-SA cathodes $(7: 3)$ show high specific capacity (157.2 $\mathrm{mAh} \mathrm{g}^{-1}$ at $500 \mathrm{~mA} \mathrm{~g}^{-1}$ rate, $0.5-3.2 \mathrm{~V}$ ) after 100 cycles. This modification method improves cycling performance by improving organic electrode materials.
\end{abstract}

Keywords: sodium-ion battery; disodium rhodizonate; reduced graphene oxide; sodium alginate; cathode material

\section{$\underline{\text { FULL TEXT }}$}

(C) 2021 The Authors. Published by ESG (www.electrochemsci.org). This article is an open access article distributed under the terms and conditions of the Creative Commons Attribution license (http://creativecommons.org/licenses/by/4.0/). 